CHAMBERS, Sally. Catalogue 2.0: the future of the library catalogue. London: Facet. 2013. 212 pages. ISBN-13 9781856047166.

This is a collection of essays on the library catalogue, considering the current position and what the future may be. It is timely to discuss if it has a future or whether it is being replaced by a combination of resource discovery tools, Google and the Web generally.

Chapters from a range of impressive international experts, including Anne Christensen, Marshall Breeding and Rosemie Callewaert, are surrounded by an introduction by Sally Chalmers and concluding thoughts from Lorcan Dempsey.

The introduction sets the scene well and is aptly followed by a chapter on the catalogue from the point of view of the users. Although written by different authors, the chapters go together well and begin to feed off each other. A chapter on the current state of resource discovery tools by Marshall Breeding goes well with a chapter by Rosemie Callewert on FRBR. More technical material is presented in a very accessible way, explaining clearly such topics as the semantic web, linked data and the different ways to achieve mobile catalogues. I especially liked the way Till Kinstler explained the shortcomings of Boolean searching and how relevance ranking works. The needs of researchers are covered by a chapter by Karen Calhoun, who advocates a larger role for open access repositories in supporting digital scholarship.

This collection will appeal to a range of library staff, including subject librarians and senior staff as well as those involved in cataloguing, and to library school students. Basically, I would recommend it to anyone who wants to take a step back from their day-to-day work and to look more critically and widely at the catalogue and its future. It gives cataloguers, in particular, a chance to reflect on what they do in more depth and to see how the data hidden in the catalogue may be used in different ways.

I have a few quibbles. The chapter on resource discovery tools could have been more critical and analytical. Rather than having snapshots of the main products, I would have liked more consideration of the problems with relevance ranking, precision, finding known items and of other issues such as whether they really deliver FRBR or only a pseudo-version of it. Having been in cataloguing for most of my career, I would have liked a chapter looking at the future of the cataloguer as a role or career. Or, to put it in less selfish terms, it would have been interesting to hear what skill sets will be needed to deal with metadata in an effective way.

The big new developments, such as the implementation of RDA, are moving a pace and the book is bound to date to some degree. This is inevitable and does not detract from the book's usefulness. A slim volume, the intention is not to be definitive but instead to cover the broad ground. As you would expect, the chapters are backed up by detailed references. The reader is pointed to plenty of further reading.

Lorcan Dempsey's final chapter leaves you with plenty to think about and takes a basically optimistic note. There is an interest in putting catalogue data in other 
places, which can lead back to library resources. There are moves to use authority files in new ways and to make more use of usage and catalogue data to make collection decisions. The catalogue itself is becoming less important as the destination point, with implications for libraries in terms of investment and direction.

In conclusion, the book is a snapshot of where we are now and where we may be heading. For providing that, the contributors are to be commended.

\section{David Pester}

Bibliographic Services Manager

London Metropolitan University

d.pester@londonmet.ac.uk 